\title{
Projeto pedagógico
}

Inayá Bittencourt e Silva*

"Elaborar um sistema pedagógico é definir um projeto de sociedade e tirar dele as conseqüências pedagógicas"

B. Charlot

A elaboração de um Projeto Pedagógico de qualidade parte de princípios democráticos e compreende questões relativas a: organização e funcionamento da escola como um sistema social, currículo, conteúdo, planejamento e avaliação (MOURA, 1990, p.27).

De acordo com a afirmação de Charlot, acima citada, existe uma interrelação estreita e recíproca entre tipo de sociedade e tipo de educação oferecida. Os princípios democráticos são ditados por e se inspiram em uma sociedade que se organize em moldes democráticos. Ou seja, uma sociedade democrática estabelecerá bases democráticas para sua política educacional. Lembremos, porém, que, por outro lado, só uma educação democrática produzirá espíritos democráticos, que garantam a continuidade do processo.

Na impossibilidade de alterar a organização da sociedade a curto prazo, mas, procurando ocupar o espaço que nos cabe como educadores, para que os projetos sociais sejam politicamente corretos, é importante então, que eduquemos para a democracia.

O Projeto Pedagógico, portanto, para se constituir em um instrumento que traga uma contribuição para as mudanças reclamadas e que a educação deve realizar, precisa, acima de tudo, se orientar pelo princípio da democratização do ensino. Em conseqüência, é interessante que se pense na interpretação que é dada a tal princípio.

Uma das concepções mais aceitas é aquela que concebe a democratização do ensino como extensão da escola para todos. Atualmente, a escola para

* Mestre em Sociologia Rural e Urbana pela UNESP de Araraquara. Doutora em Ciências Sociais pela Pontifícia Universidade Católica de São Paulo. Professora do Centro Universitário de Araraquara e Coordenadora do Centro de Pensamento Político da mesma Instituição. E-mail: inayabs@gmail.com. 
todos é considerada um direito dos cidadãos e um dever do Estado. Significa escola pública, gratuita, de boa qualidade e de modelo único. Uma escola que funcione de forma a assegurar que todos tenham acesso a ela, garantia de aí permanecerem e condições de igualdade para a aprendizagem.

Mas, o conceito de escola democrática não se esgota no aspecto de ampliação das oportunidades e de melhoria de tratamento ao aluno, em relação ao acesso, permanência e atendimento recebido. Diz respeito também à sua função de formação de cidadãos conscientes, participativos e democráticos. Será uma escola que trabalhe o conhecimento geral que deve ser oferecido a todos, com o objetivo de promover a socialização, a fim de contribuir para a superação do dualismo existente na sociedade e não de reproduzi-lo (PIMENTA, 1990, p.18-19).

Com essa determinação, a educação oferecida deve desenvolver nos alunos condições para compreender o mundo e a sociedade em que estão historicamente situados, oferecendo-lhes condições de interferirem no meio em que atuam.

Analisando a escola brasileira à luz desse conceito, verificamos que, embora a partir de algumas décadas, mais precisamente após 1930, ela tenha ampliado a oferta de vagas, essa ampliação não aconteceu na medida exata das necessidades existentes e, o que foi realizado só fez manter a educação no limite da sobrevivência, ou seja, em condições precárias. Houve uma degeneração do ensino no Brasil.

Reafirmamos que, o ponto de partida ideal e obrigatório para a construção do Projeto Pedagógico é dar ênfase ao objetivo de construir uma escola pública democrática.

A elaboração do Projeto Pedagógico compreende algumas questões, citadas acima, que devem, todas elas, ser direcionadas para aquele tipo de educação pretendida, com a finalidade de compor o espaço adequado à sua consecução.

A primeira questão, relativa à organização e ao funcionamento da escola, deve ser pensada em termos de uma organização pedagogicamente competente para mudar a realidade presente, partindo de suas próprias imperfeições e deficiências. Essa organização compreende o trabalho pedagógico do cotidiano dos profissionais que acreditam que podem fazer com que a educação seja um instrumento de emancipação dos alunos oriundos das camadas populares e que estejam comprometidos com isso. Pesquisando, analisando, observando e fazendo experimentações a partir da escola atual, que expulsa os alunos das camadas inferiores que, pela ampliação quantitativa das vagas tiveram acesso a ela, é que poderemos organizá-la em novos moldes (PIMENTA, 1990, p.22-23).

A organização e o funcionamento da escola é um trabalho coletivo que diz respeito a tarefas docentes e não docentes. Não pode ser reduzida ao trabalho em sala de aula; pelo contrário, precede e ultrapassa esse trabalho. Além das atividades docentes, realizadas pelos professores, compreende outras atividades, realizadas também por outros profissionais da educação. São elas: seleção, distribuição, organização e articulação dos conteúdos considerados relevantes para a construção de uma prática social transformadora. A seleção desses conteúdos deve ser feita a partir do que pode ser considerado como historicamente necessário para alterar a situação de desigualdades sociais, articulado com o que é historicamente possível, de ser ministrado. Outras atividades, não docentes, relativas à organização e funcionamento que podem contribuir para a democratização da escola são: a maneira como as turmas são formadas, em relação ao número de alunos por classe e à condição de homogeneidade ou de heterogeneidade dos alunos; a elaboração do calendário escolar e do horário de aulas. Os critérios utilizados para a realização dessas tarefas podem contribuir para a permanência ou evasão da clientela menos favorecida, se dificultarem, mais ainda, suas condições de existência (PIMENTA, 1990, p.22-24).

A atenção e o respeito, às condições de vida dos alunos das classes trabalhadoras, não incluem a atitude assistencialista nem o oferecimento de um ensino superficial, de segunda qualidade, a título de facilitar sua vida. O importante é conseguir conciliar os ensinamentos necessários ao seu crescimento, com as limitações sociais a que estão sujeitos.

Uma outra atividade que deve ser incluída quando se fala em termos de organização e funcionamento da escola é a necessidade de compatibilizar exigências burocrático-administrativas com os conteúdos educativos a serem ministrados. A compatibilização dessas atividades díspares, mas, correlatas, consideradas como dois pólos de pressão, na medida em que ambas apresentam níveis consideráveis de importância, não podem ser descuidadas, para que se consiga conciliar competência técnica com clareza política. Embora esta seja uma tarefa cuja responsabilidade recaia mais diretamente sobre os ombros da direção da escola, repousa também nos ombros dos professores. Além das funções de caráter essencialmente docente, entre as quais se inclui a escolha, o ministério e a articulação horizontal e vertical da matéria e dos conteúdos a serem ensinados, existe uma função burocrática que os professores devem desempenhar. Refere-se a registros e relatórios sobre a observação da freqüência e do desempenho dos alunos, feita através do acompanhamento e das avaliações dos mesmos. Diz respeito ainda à elaboração dos planos de ensino, preparo de aulas e correção de provas (MOURA, 1990, p.25).

Em relação aos conteúdos é necessário destacar que a sua seleção deve ser feita tendo em vista as necessidades históricas e sociais do tipo de sociedade no qual a escola se insere. $\mathrm{O}$ atendimento e as respostas a essas necessidades são dados de forma cultural, isto é através do resultado do trabalho das pessoas. 
Além das necessidades naturais os homens têm necessidades criadas que constituem o móvel das ações e relações entre os indivíduos. As necessidades, de modo geral, se classificam em necessidades concretas e necessidades empíricas. As necessidades concretas são aquelas que não são definidas para uma pessoa, uma classe ou uma sociedade, mas, para todos os elementos de uma sociedade de modo a contribuir para a determinação do perfil de sua cultura como conhecimentos, crenças, valores etc. As necessidades empíricas são aquelas determinadas por situações conjunturais vividas pelos indivíduos. Um grande desafio para os educadores é atender às necessidades concretas dos educandos, pela definição de conteúdos que se articulem com os demais elementos de um currículo (RIOS, 1990, p.41).

Não menos fácil é o atendimento das necessidades empíricas que não devem ser desconsideradas, pois são relevantes para a consecução da educação democrática. Como já mencionado acima, cumprir esse atendimento, não pode ser confundido com um simples assistencialismo.

A importância dos conteúdos se manifesta, principalmente, pelo fato de que, ao definir o que ensinar, o educador está levando em conta os fundamentos de sua prática. A definição dos conteúdos, porém, não pode se desvincular de questões que dizem respeito às condições reais da escola, ao ideal de democratização do ensino, à metodologia a ser utilizada e à questão da avaliação.

Considerando que a escola e a sociedade, da qual faz parte, são fatos historicamente variáveis, o conteúdo também deve variar, necessitando, portanto, ser constantemente retomado e atualizado. "Essa atualização não significa concessão à moda ou flutuação ao sabor dos ideólogos, mas, atenção à transformação da sociedade, por interferência dos homens que a constituem, nas condições concretas em que se encontram” (RIOS, 1990, p.42-43).

Outra questão importante em relação aos conteúdos é a necessidade de que sejam discutidos articuladamente com os outros elementos que compõem o currículo. As ações seguintes não podem ser desvinculadas entre si:

- o que se ensina (conteúdo)

- como se ensina

- para que se ensina

- por que se ensina

- quem ensina

- a quem se ensina.

Tais ações sintetizam a prática pedagógica e traduzem os dois aspectos fundamentais, de interação recíproca, pretendidos com o processo ensinar/ aprender (RIOS, 1990, p.39).

A organização e o funcionamento da escola incluem ainda uma segunda exigência, além daquela de compatibilizar os dois pólos de pressão.
É a responsabilidade ética de democratizar também as relações internas na escola.

A democratização das relações internas passa pela co-gestão, pelo diálogo e pela criação de condições que possibilitem o repensar crítico da prática pedagógica, em todos os seus aspectos, tais como: priorização de conteúdos, organização curricular, adequação metodológica e aperfeiçoamento do processo de avaliação do rendimento escolar (MOURA, 1990, p.30).

Embora a responsabilidade ética de promover a democratização das relações internas possa caber à direção da escola, ela não se efetivará se, em contrapartida, os professores não aceitarem que também sejam analisadas e discutidas, por toda a comunidade escolar, a sua própria prática. A finalidade é romper com a dicotomia, constantemente existente, entre quem planeja e quem executa; é fazer com que todos sejam co-responsáveis pela construção do Projeto Pedagógico e que sejam superadas a desarticulação e a fragmentação observadas na prática educativa.

A segunda questão a ser focalizada para preparar o Projeto Pedagógico é a elaboração do currículo. Através de uma reflexão conjunta, a equipe escolar deve analisar a sua realidade: saber quem é o aluno desta escola, seus valores, seus ideais, suas expectativas e necessidades. Qual o nível de heterogeneidade apresentado pela clientela.

A obtenção desses indicadores orientará o estabelecimento dos objetivos que a escola pretende atingir, considerando as necessidades dos alunos. Os objetivos a serem atingidos orientarão a composição do currículo.

A partir de uma nova postura, de observação crítica e de reflexão coletiva, em que são tomadas decisões conjuntas, é que serão determinados os elementos básicos do currículo, que se inicia com a seleção dos conteúdos. Esta escolha é feita respondendo às questões:

- para saber o que?

- para saber fazer o que?

- quais princípios orientaram a seleção, distribuição e organização dos conteúdos pelas várias disciplinas do currículo?

- existe articulação dos conteúdos com os objetivos educacionais?

- a metodologia é adequada à construção do conhecimento?

- está havendo apreensão crítica dos conteúdos, pelos alunos?

- as avaliações estão sendo feitas no sentido de reorientar a prática docente? (MOURA, 1990, p.28).

Quando esta prática ocorre, fica ressaltado o significado social do papel do educador e de sua dimensão político-pedagógica, calcada no compromisso ético de formar cidadãos.

As últimas questões a serem consideradas na elaboração do Projeto Pedagógico são: o conteúdo, o planejamento e a avaliação, que se articulam 
através de uma relação empírica, embora, as atividades anteriormente mencionadas, organização e funcionamento da escola e currículo também estejam relacionados entre si e com o conteúdo. É em torno da escolha dos conteúdos e de seu ministério, que se desenvolve quase todo o processo educativo. Parte significativa da organização e funcionamento da escola é determinada pelo conteúdo a ser desenvolvido. Quanto ao currículo pode ser entendido como um conjunto de conteúdos dispostos harmonicamente e situados de forma orgânica.

Ao formalizar o planejamento, o que se discute é o conteúdo a ser ensinado e a maneira de fazê-lo. Por outro lado, ao proceder à avaliação, examina-se o conteúdo que foi realmente ensinado e aprendido.

O planejamento, tem sido visto como um meio para facilitar e viabilizar o atingimento dos objetivos educacionais desejados. $\mathrm{Na}$ atual conjuntura, interessa-nos a questão dos objetivos de uma educação democrática. $\mathrm{O}$ planejamento implica, então, um processo de reflexão filosófica, isto é uma reflexão radical, rigorosa e de conjunto. Radical, no sentido de refletir sobre a raiz do problema. Rigorosa, por usar o método científico. De conjunto, por exigir visão da totalidade na qual o fenômeno aparece. É, pois, um processo amplo e complexo; mais amplo e complexo que um plano de ensino. Enquanto planejamento é o processo que compreende elaboração, execução e avaliação do plano de ensino, este representa o momento de registro do processo educacional, ou seja, é um documento (FUSARI, 1990, p.45-46).

A formalização dos planos de ensino não precisa, necessariamente, se enquadrar em formulários que limitam a reflexão e a criatividade dos professores. O importante é que explicitem os itens seguintes:

- "objetivos da educação escolar (para que ensinar e aprender?)"

- "conteúdo (o que ensinar e aprender?)"

- "métodos (como e com o que ensinar e aprender?)"

- "tempo e espaço da educação escolar (quando e onde ensinar e aprender?)"

-"avaliação (como e o que foi efetivamente ensinado e aprendido?)" (FUSARI, 1990, p.46).

A avaliação é o último item a ser considerado para elaboração de um Projeto Pedagógico. Ela não possui uma finalidade em si mesma. Quando se pretende avaliar a aprendizagem, a avaliação subsidia decisões que visam garantir a qualidade dos resultados de um processo que estamos desenvolvendo. Ela deve, então, ser estudada articulada com um projeto. Deve servir de base para tomadas de decisões, no sentido de construir nos educandos conhecimento, hábitos e habilidades que promovam seu desenvolvimento efetivo, na medida em que assimilem a herança cultural da sociedade (FUSARI, 1990, p.71).

Tendo em vista o interesse que desperta o aperfeiçoamento do processo avaliatório, é importante que se faça uma análise do tratamento que tem sido dispensado aos resultados da aprendizagem dos alunos. $\mathrm{O}$ que temos praticado na escola: verificação ou avaliação da aprendizagem? A conclusão, a que pudemos chegar, poderá servir de orientação para o aperfeiçoamento do processo? (LUCKESI, 1990, p.71-72).

Verificar é uma palavra que vem do latim "verum facere" que significa "fazer verdadeiro"; se refere à busca intencional; ver se algo é verdadeiro; investigar a verdade de alguma coisa. A verificação se encerra no momento em que se conclui que tal objeto possui uma configuração determinada, isto é, a verificação está pronta quando se obtém a informação pretendida, quando se constata alguma coisa.

A palavra avaliar, por sua vez, também de origem latina "a valere", quer dizer "dar valor a" partindo de um posicionamento positivo ou negativo em relação a um objeto. Mas, ela não se encerra nessa atribuição de valor; ela exige, em conseqüência, uma decisão de ação (LUCKESI, 1990, p.75-76).

Para avaliar são necessárias as seguintes ações: coleta, análise e síntese dos dados que definem o objeto de avaliação, acrescido de uma atribuição de valor, feita a partir da comparação com um padrão de qualidade, previamente escolhido. Essa atribuição de valor leva a uma tomada de posição, a favor ou contra o objeto.

A diferença entre verificar e avaliar, portanto, é que, enquanto a verificação é um processo estático, que congela o objeto dentro de uma idéia, de uma determinada imagem, a avaliação não se esgota na obtenção da configuração do objeto, mas, direciona o objeto para uma ação.

Se os resultados da aprendizagem forem utilizados apenas para estabelecer uma classificação do educando, encerrando-se com o registro dos resultados, então, teremos feito somente uma verificação. Quando a aferição da aprendizagem se constitui em um mecanismo de compreensão dos avanços, limites e dificuldades dos alunos, que orienta a ação a ser desenvolvida, temos um efetivo ato de avaliação.

Partindo dessas observações, podemos afirmar que, a maior parte das vezes, a prática educacional brasileira tem feito apenas uma verificação da aprendizagem, sem aferir quais seriam as possibilidades de melhoria da qualidade do desempenho do aluno. A verificação, contrariamente ao desejável, tem contribuído apenas para criar nos alunos um constante sentimento de medo pela ameaça de reprovação, sem trazer, da mesma forma, nenhuma compensação para o professor (LUCKESI, 1990, p.75-76).

Partindo das rápidas considerações até aqui expostas, concluímos que, na elaboração do Projeto Pedagógico devem merecer atenção especial, os seguintes aspectos: 
- princípios filosóficos nos quais se baseia o trabalho pedagógico realizado - visão do mundo, do homem e da sua condição de cidadão.

- articulação do corpo docente e técnico administrativo entre si e,

- compromisso de todos com o planejamento pedagógico.

- princípios pedagógicos e diretrizes metodológicas: currículo (para que?); conteúdo (o que?); metodologia (como? com que? onde?) e avaliação.

- articulação entre os componentes curriculares e os níveis de ensino.

A elaboração de um Projeto Pedagógico põe em destaque a função social e a dimensão política da prática de todos os educadores de modo geral. Exige que, além de preparar alunos, a comunidade escolar forme, também, cidadãos. Prevê a compatibilização de interesses e possibilidades como também a conciliação das tensões existentes na vida social e no cotidiano da escola.

Concluindo, porém sem esgotar o assunto, verificamos que a elaboração de um Projeto Pedagógico que traga uma contribuição para a melhoria do ensino, exige uma reflexão sobre a responsabilidade ética dos profissionais da educação. Essa reflexão salienta o caráter bilateral da ação educativa, mostrando a impossibilidade de separar suas duas faces: ensinar/aprender. Só a interação recíproca entre elas atesta que o processo educacional foi completado.

Embora as ações ensinar/aprender sejam consideradas como o centro, o móvel e seu objetivo último, a educação não se restringe a elas. As atividades educacionais, com sua complexidade e natureza específica, se realizam em um contexto quase sempre adverso, e exigem de seus profissionais competência técnica e clareza política. Nesse contexto, um dos desafios é a necessidade de compatibilizar os pólos de pressão que se estabelecem no cotidiano das escolas. A superação da dicotomia existente entre ações de planejar e de executar é outro desafio responsável pela eliminação da desarticulação e fragmentação constantemente verificadas no processo educacional. Todas essas responsabilidades têm como finalidade última, a de cumprir o compromisso ético de formar o cidadão.

Observando todas essas condições, necessárias à realização do processo educacional, ganha destaque o significado social do papel do educador, em sua dimensão político-pedagógica.

\section{Referências:}

FUSARI, José Cerchi. O planejamento do trabalho pedagógico: algumas indagações e tentativas de respostas. Idéias, São Paulo, n.8, p.44-58, 1990.

LUCKESI, Cipriano C. Verificação ou avaliação: o que pratica a escola? Idéias, São Paulo, n.8, p.133-140, 1990.

MOURA, Elaine M. S. de. Uma reflexão conjunta sobre o cotidiano da escola de $1^{\circ}$ grau. Idéias, São Paulo, n.8, 1990.

PIMENTA, Selma G. A construção do projeto de ensino na escola de $1^{\circ}$ grau. Idéias, São Paulo, n.8, p.17-24, 1990.

RIOS, Terezinha A. A importância dos conteúdos socio-culturais no processo avaliativo. Idéias, São Paulo, n.8, p.37-43, 1990.

\section{Resumo:}

Este ensaio apresenta uma reflexão a respeito da elaboração de um Projeto Pedagógico. Ressalta a importância do projeto como um instrumento que possibilita trazer uma contribuição para as mudanças reclamadas pela sociedade e que devem ser realizadas pela educação; salienta a necessidade de que o mesmo se oriente pelo princípio de democratização do ensino e em conseqüência da educação.

\section{Palavras-chave:}

Organização, Currículo, Conteúdo, Planejamento, Avaliação. 